\title{
SUBJECT-ORIENTED CLASSIFICATION OF PUNS USED IN SPANISH-SPEAKING ADVERTISEMENTS
}

\author{
Aleksandr V. Dzyuba \\ Southern Federal University, Rostov-on-Don, Russia
}

\begin{abstract}
While analyzing wordplay in advertisements, researchers tend to focus on formal classifications. One of the few modern groupings that diverge from this formal approach is the typology made within the framework of Relevance Theory. This paper provides new classification based on the subject of punning. The comprehensive analysis of 609 slogans reveal three types of wordplay used in Spanish-speaking advertising discourse: merchandise (goods) wordplay, brand (trademark) wordplay and unlinked wordplay. Using merchandise puns, copywriters play with the names of products. Also, these types of puns exploit ambiguous words and the associations which already exist in the minds of the target audience, e.g. comida (food) - rico (rich / tasty). Thanks to the merchandise wordplay, recipients can deduce what is advertised without having the explicit product names in the slogans. Brand wordplay uses lexemes chosen for the trademark or associations produced by such lexeme, e.g. vine brand Bach is associated with music, and therefore, copywriters introduce music allusions in slogans. This method helps to memorize a brand-name and make it stand out. The last type of wordplay, unlinked puns, have no connections with brand-names or goods and is often present in a less creative way of playing on words. The main aim of the unlinked wordplay is to entertain the target audience. A quantitative analysis shows that merchandise wordplay occurs in the majority of cases and unlinked wordplay is the least popular type. Such distribution may be caused by different cognitive-pragmatic potential of wordplay types as hypothesized in current research.

Key words: wordplay, puns, advertising, Spanish language, classification, cognitive-pragmatic potential, relevance theory.

Citation. Dzyuba A.V. Subject-Oriented Classification of Puns Used in Spanish-Speaking Advertisements. Vestnik Volgogradskogo gosudarstvennogo universiteta. Seriya 2, Yazykoznanie [Science Journal of Volgograd State University. Linguistics], 2018, vol. 17, no. 2, pp. 107-115. (in Russian). DOI: https://doi.org/10.15688/ jvolsu2.2018.2.12
\end{abstract}

УДК $811.134 .2 ’ 42: 659.123 .1$

Дата поступления статьи: 20.01.2018

ББК 81.472.1-55

Дата принятия статьи: 30.03 .2018

\section{ОБЪЕКТНО-ОРИЕНТИРОВАННАЯ КЛАССИФИКАЦИЯ ИГРЫ СЛОВ В РЕКЛАМЕ (НА МАТЕРИАЛЕ ИСПАНСКОГО ЯЗЫКА)}

\author{
Александр Владимирович Дзюба \\ Южный федеральный университет, г. Ростов-на-Дону, Россия
}

\begin{abstract}
Аннотация. Статья посвящена актуальной лингвистической проблеме построения неформальной классификации рекламы, содержащей игру слов. С опорой на положения теории релевантности и с применением когнитивно-прагматического подхода к изучению языковых единиц автором разработана классификация, которая учитывает характер объекта, обыгрываемого в рекламном слогане. Выделены три типа игры слов: $\infty$ товарно-ориентированная, брендово-ориентированная и несвязанная. В результате компонентного анализа ㄱ 607 испаноязычных рекламных слоганов установлено, что при товарно-ориентированной игре слов копи๓ं райтеры обыгрывают наименование товара, используя ассоциативные связи, характерные для индустрии и уже закрепленные в сознании носителей языка, позволяя реципиенту догадываться о том, что рекламирует§ ся, без эксплицитного обозначения товара. При брендово-ориентированной игре слов обыгрывается название бренда и ассоциации, связанные с ним, что способствует его запоминанию. При несвязанной игре слов (0) используются игровые возможности языка независимо от наименования товара или названия бренда и
\end{abstract}


достигается цель развлечения реципиента. Приведенные в статье количественные данные свидетельствуют о том, что наиболее частотной является товарно-ориентированная игра слов, а наименее частотной - несвязанная. Показано, что такое распределение обусловлено когнитивно-прагматическим потенциалом указанных приемов.

Ключевые слова: игра слов, каламбур, реклама, испанский язык, классификация, когнитивно-прагматический потенциал, теория релевантности.

Цитирование. Дзюба А. В. Объектно-ориентированная классификация игры слов в рекламе (на материале испанского языка) // Вестник Волгоградского государственного университета. Серия 2, Языкознание. 2018. - T. 17, № 2. - C. 107-115. - DOI: https://doi.org/10.15688/jvolsu2.2018.2.12

\section{Введение}

Реклама как один из видов коммуникации занимает важное место в жизни современного общества. Она принимает разнообразные формы и передается реципиентам по различным каналам. Для того чтобы многие рекламные сообщения достигли адресата и не остались не замеченными потенциальными потребителями, создатели рекламных текстов - копирайтеры - стараются придумать слоганы, которые могли бы понравиться аудитории и одновременно привлечь ее внимание, акцентировать его, например, на названии рекламируемого бренда или типе товара. Одним из популярных средств привлечения внимания возможных покупателей является игра слов.

Повышенную частотность использования игры слов в рекламе можно объяснить тем, что данное экспрессивное средство обладает высоким когнитивно-прагматическим потенциалом, под которым чаще всего понимается «возможность актуализации в речи не только категориальных значений, присущих языковым единицам как элементам языковой системы или языковой картины мира, но и тех импликатур, которые могут проявиться при взаимодействии языка с речевой средой, способствуя тем самым формированию определенного восприятия, осмысления и познания действительности, а также достижению определенного прагматического эффекта» [Карповская, 2015, с. 109].

Примечательно, что игра слов, как и любая языковая шутка, воспринимается как нечто «свое», понятное только определенному кругу лиц, принадлежащих к одной нации или одному сообществу. Поэтому создатели рекламы стараются учитывать национальные особенности тех стран, для которых создается реклама. Так, создатели рекламы в Испа- нии обыгрывают ассоциации, связывающие эту страну с хорошей погодой, солнцем и обилием света. Особенно это заметно в Андалусии, само название которой порождает игровые рекламные сообщения и названия брендов: радио Ondaluz (букв.: волна + свет), магазин осветительных приборов ANDAluz (букв.: идет + свет) и т. д. Кроме того, создаются рекламные стенды, на которых парадоксальным образом написано:

(1) Cruzcampo: Esto no es un anuncio. Es una sombra patrocinada

(Cruzcampo: Это не рекламное объявление. Это тень, оплаченная спонсором).

Житель Испании естественно ассоциирует пиво с жарой, а значит, будет благодарен даже рекламе пива, позволяющей спрятаться за ней от солнца.

Таким образом, благодаря высокому когнитивно-прагматическому потенциалу игры слов копирайтерам удается сформировать у реципиентов положительное отношение к рекламируемой продукции.

Решая задачи классификации рекламы, содержащей игру слов, многие исследователи уделяют внимание только формальным различиям средств, создающих игру слов, и на их основе предлагают формальные классификации [Ильясова, Амири, 2016; Glowicka, 2002; Xiang, 2006; Yan, 2015]. Однако объяснительная сила таких классификаций невелика. Одной из немногих классификаций, в которой учитываются неформальные, в частности прагматические, признаки рекламы, является классификация рекламных слоганов, содержащих игру слов, разработанная с позиции теории релевантности и впервые выдвинутая К. Танака в 1992 году. Согласно японскому исследователю, при интерпретации таких слоганов реципиенты могут либо одновре- 
менно учитывать обе возможные интерпретации слогана в случае обыгрывания полисемии или двойной актуализации устойчивого выражения, либо же отбросить одну из этих интерпретаций как нерелевантную в данном контексте [Tanaka, 1992, p. 98-101]. Следовательно, игра слов в рекламе может 1) иметь как минимум две релевантные интерпретации или 2) иметь только одну релевантную интерпретацию. Впоследствии М. ван Мулкен и его коллеги на материале нидерландского рекламного дискурса доказали, что реципиенты в случае обнаружения игры слов отдавали предпочтение слоганам, содержащим две релевантные интерпретации, но при этом слоганы с игрой слов, которая имеет только одну возможную интерпретацию, казались испытуемым более интересными, чем рекламные сообщения, в которых данное экспрессивное средство отсутствовало [Van Mulken, Van Enschot-van Dijk, Hoeken, 2005, p. 715]. Отметим, что в упомянутом исследовании рассматривались только слоганы с игрой слов, возникающей благодаря языковой неоднозначности, и, следовательно, не анализировались каламбуры и парономазия.

В работах Ф. Юса, также выполненных в русле теории релевантности, утверждается, что можно выделить по меньшей мере четыре типа игры слов в зависимости от пропорциональности эффекта высказывания и когнитивных усилий, затраченных на его интерпретацию: 1) высказывание предполагает две возможные интерпретации, одинаковые по эффекту и затратам, в результате чего реципиент не может выбрать только одно релевантное значение, воспринимая обе интерпретации как шутку; 2) реципиенту удается быстро интерпретировать высказывание, однако он все равно продолжает искать другую интерпретацию, например, комическую (к этому типу относятся игра с буквальным и метафоричным значениями слов и устойчивых выражений, полисемией, омонимией); 3) высказывание изначально не дает никакой интерпретации, совместимой с принципом релевантности, в связи со своей абсурдностью, однако реципиент, учитывая комическую направленность игры слов, продолжает искать релевантную интерпретацию; 4) стимулятор шутки содержит потенциально двусмысленный термин, первая возможная интерпретация которого отвергается реципиентом игры слов в пользу менее вероятной (однако возможной) интерпретации [Yus, 2003, p. 1321-1324].

Возможности применения классификации Ф. Юса к анализу рекламы охарактеризованы в [Van Mulken, Van Enschot-van Dijk, Hoeken, 2005]. Ученые указывают на то, что в рекламе часто встречаются только первые два вида игры слов (они совпадают с классификацией К. Танака). Третий тип является достаточно редким. Четвертый тип встречается только в обычных разговорах коммуникантов [Van Mulken, Van Enschot-van Dijk, Hoeken, 2005, p. 710].

Исследования в рамках теории релевантности внесли значительный вклад в изучение игры слов в целом и ее употребления в рекламе в частности. Полученные выводы и классификации могут быть использованы и в работах, находящихся за рамками указанной теории, в особенности в тех, что обосновывают связь затраченных когнитивных усилий и эффекта игры слов, а также выбор той или иной интерпретации реципиентом.

Несмотря на определенную разработанность темы применения игры слов в рекламе, не все важные вопросы, касающиеся данного экспрессивного средства, попали в поле зрения исследователей. Так, до сих пор не предложена классификация игры слов в рекламных слоганах, основным критерием которой являлся бы сам объект обыгрывания. В настоящей статье, опираясь на положения теории релевантности и используя когнитивно-прагматический подход к изучению языковых единиц, мы предлагаем новую объектно-ориентированную классификацию игры слов в рекламе.

Материал для исследования отобран методом сплошной выборки из журналов, газет, ТВ-рекламы с билбордов и интернет-сайтов (самые ранние примеры датируются 1940 г., однако подавляющее большинство примеров относятся к 1980-2017 гг.).

\section{Объектно-ориентированная классификация рекламы, содержащей игру слов}

В результате компонентного анализа 607 испаноязычных рекламных слоганов, со- 
держащих игру слов, можно представить следующую типологию использования указанного экспрессивного средства в зависимости от обыгрываемого объекта высказывания: товарно-ориентированная игра слов, брендово-ориентированная игра слов и несвязанная игра слов.

I. Под товарно-ориентированной мы понимаем игру слов, при которой либо прямо обыгрывается наименование рекламируемого товара или услуги, либо используются ассоциации и понятия, общие для конкретной индустрии. Среди таких общих ассоциаций, уже закрепленных в языке и сознании информантов, можно назвать связи comida (еда) - rico (богатый / вкусный / насыщенный), óptica (оптика) - vista (взгляд / вид), bancos (банки) crédito (кредит / доверие), interés (интерес / процент) и т. п. Наиболее часто в игровых слоганах употребляются многозначные лексемы, как минимум одно из значений которых и связано каким-либо образом с рекламируемым товаром. Эти связи используются копирайтерами для создания слоганов и способствуют их вторичному закреплению в сознании носителей испанского языка. Обыгрывание наименования товара (например, масло, хлеб, водка и т. п.) помогает потребителю при небольших когнитивных усилиях понять, о чем идет речь в слогане. Благодаря своей оригинальности и зачастую остроумности рекламный текст может запомниться и вызвать положительное отношение к рекламируемой продукции.

В формальном плане применение игры слов того или иного вида в рекламе никак не ограничено, поэтому в слоганах могут встречаться каламбуры, парономазии, окказиональное варьирование и двойная актуализация устойчивых выражений, игровые аллюзии на прецедентные тексты, парадоксы, обыгрывание полисемии и омонимии (неоднозначности), псевдосинонимии и псевдоантонимии. Причем иногда копирайтеры используют одновременно несколько приемов.

Рассмотрим конкретные примеры товарно-ориентированной игры слов, отмечая специфику ее употребления в испаноязычной рекламе. С большой частотностью в таких слоганах используются двойная актуализация и окказиональное варьирование устойчивых выражений.
(2) Alimentos de España: Nobleza Oliva (букв.: Благородство Оливковое масло).

В слогане (2) обыгрывается поговорка Nobleza Obliga (фр. Noblesse oblige), которая на русский традиционно переводится, как «положение обязывает» (букв.: благородное положение обязывает). Используя созвучие слов oliva и obliga, создатели рекламы демонстрируют «благородство» и высокое качество настоящего испанского оливкового масла.

(3) Asturiana: Nuestro verano es la leche (Наше лето - супер / букв.: Наше лето - это молоко).

В слогане (3) происходит разложение устойчивого выражения ser la leche, наиболее актуальное значение (salient meaning) которого в повседневной речи носителей испанского языка - «быть отличным». Однако, поскольку это реклама молочной продукции, потребители понимают, что буквальное значение устойчивого выражения является не менее актуальным в данном контексте, и потому происходит его двойная актуализация. Стоит отметить, что подобное использование данной фразеологической единицы постепенно теряет свою оригинальность. Можно привести еще несколько примеров подобной игры слов: Manteleira: Ser solidario es la leche (Быть солидарным - классно / букв.: Быть солидарным - это молоко); Asturiana: Nuestra vida es la leche (Наша жизнь - это классно / букв.: Наша жизнь - это молоко). Высокая частотность выражения в речи носителей испанского языка даже позволила авторам одного из пособий по изучению английского языка «буквально» перевести название своей книги на английский как "This book is the milk".

(4) Aqua Bona: Transparente como el agua (Прозрачный, как вода).

Парадоксальность этого слогана привлекает внимание, ведь обычно «прозрачным, как вода» называют все, что угодно, кроме воды. Однако таким образом подчеркивается высший сорт минеральной воды Aqua Bona.

(5) Eudermin: Para empezar un día con buen pie (Для того, чтобы хорошо начать день / букв.: Для того, чтобы начать день с хорошей ноги). 
В рекламном тексте (5) обыгрывается устойчивое выражение con buen pie (удачно, хорошо), которое связано с существующим у многих народов поверьем о том, что день нужно начинать, наступив на пол определенной (подразумевается «правой») ногой (ср. рус. встать не с той ноги). Однако в рекламном слогане на верную его интерпретацию влияет рекламируемая продукция - крем для ног Eudermin: реципиент должен интерпретировать сочетание con buen pie как в буквальном смысле, так и в переносном смысле. Возникает корреляция «зздоровая кожа ступней» > «удачный день», которая формирует у реципиента потребность в покупке крема Eudermin.

(6) Diamante: Hay quién sabe dar en el blanco (Есть те, кто умеет попадать в цель / букв.: попадать в белое [вино]).

Товарная ориентированность игры слов в слогане (6) проявляется в неоднозначном восприятии лексемы blanco, которая в предложенном контексте может означать как «цель», так и «белое [вино]». В любом случае возникает связь между обоими потенциальными значениями blanco, в соответствии с которой «люди, попадающие в цель», то есть добивающиеся успеха и правильно выбирающие товары, всегда «выбирают белое вино Diamante».

При помощи товарно-ориентированной игры слов может также возникать связь между известными личностями и рекламируемой продукцией.

(7) Brandy 103: El Marlón Brandy de las colas, tónicas, naranjadas, limonadas, sodas, etc., etc. (Mapлон Брэнди для колы, тоников, апельсиновых газировок, лимонадов, содовых и т. д., и т. д.).

Так, благодаря обыгрыванию фонетической близости фамилии знаменитого голливудского актера (Marlon Brando) и наименования крепкого алкогольного напитка (brandy), а также изображению Марлона Брандо на рекламном объявлении копирайтеры пытаются указать на лидирующую позицию Brandy 103 на рынке. Сравнивая или даже отождествляя бренди с актером, потенциальный потребитель может осознать, что данный напиток достоин высших наград и представляет собой продукцию самого высокого качества.
Иногда для создания игры слов используются не очень частотные лексемы, которые, однако, в определенном контексте реализуют свой когнитивно-прагматический потенциал:

(8) Derlavón: Para gente muy ducha (Для очень опытных людей).

Благодаря омонимии слов ducha (душ) и ducho в ж. p. (опытный, искусный, умелый) указанная лексема приобретает окказиональное значение «те, кто любят принимать душ», следовательно, гель Derlavón предназначен именно для таких любителей и «экспертов».

Помимо омонимии, в слоганах может обыгрываться и полисемия какой-либо определенной лексемы:

(9) La lechera: Una gran sugerencia, condensada en dos palabras (Отличное предложение, выраженное [сгущенное] в двух словах).

В приведенном примере у слова condensada актуализируются сразу два значения - «сгущенное [молоко]» и «кратко изложенное, сжато выраженное».

Фонетическая схожесть паронимов и контаминация, или телескопирование, - прием, заключающийся в соединении нескольких лексем в единый окказионализм, используются копирайтерами с не меньшей частотностью.

(10) Visa Banco Santander: Vacaciones con Visa al mar (букв.: Отпуск с Визой [видом] на море).

В слогане (10) обыгрывается устойчивое сочетание, постоянно встречающееся в туристических проспектах и использующееся в качестве демонстрации неоспоримого достоинства предлагаемого гостиничного номера - vista al mar (вид на море). Благодаря парономазии vista / Visa появляется возможность убедить потенциального клиента в том, что пластиковая карта банка Santander позволит заполучить подобный номер, на который не у всех хватает средств.

(11) Andifrut: ;Refreshcante! (Освежающе!).

Реклама нектаров Andifrut сопровождается слоганом ¡Refreshcante!, представляю- 
щим собой контаминацию испанского refrescante и английского fresh, что может быть обусловлено повышенным интересом к латиноамериканскому рынку, в котором сильнее влияние США и английского языка. Кроме того, производители соков и нектаров призывают употреблять напитки в очень холодном виде, что также ассоциативно связано с понятием «освежающий».

(12) Danone: Tus flanvoritos (Твои фланвориты).

В этой рекламе название товара flan встроено в лексему favoritos. Игра слов построена с учетом национальных особенностей потребителя: кондитерское изделие флан от Danone является любимым у многих испанцев.

II. При брендово-ориентированной игре слов обыгрывается название самого бренда, которое может включаться в каламбур, выделяться графически или заменять созвучное слово в слогане. Контаминация используется чаще, чем в рекламных слоганах товарного типа. Название бренда может быть эксплицировано в слогане, либо может быть создана семантическая аллюзия на название бренда в лексемах, используемых в слогане, например, Bach - obertura (Бах - увертюра) и созвучное последней apertura (открытие, то есть открытие бутылки вина). Игра слов данного типа способствует запоминанию бренда, он начинает выделяться на фоне своих конкурентов. Рассмотрим несколько примеров брендовой игры слов:

(13) Myrga: Myrga [mira + Myrga] que genial (букв.: Myrga [Посмотри], как классно);

(14) Ford: Confordtable [Ford + comfortable] (Комфордтабельный);

(15) SOS: Si es Sos, es bueno. Evolución sostenida (букв.: Если это SOS, это хорошо. Устойчивая эволюция).

В слоганах (13)-(15) возникает контаминация названия бренда и лексемы, которая акцентирует внимание реципиентов на рекламируемом бренде: Myrga > mira, Ford > comfortable, Sos $>$ sostenida. В случае создания подобных «слов-бумажников» происходит намеренное нарушение установленных языковых норм и возникает определенная анома- лия, которая осознается носителями языка и вызывает у них интерес, так как «восприятие мира... прежде всего фиксирует аномальные явления», а «то, что ожидают увидеть, остается незамеченным» [Арутюнова, 1999, с. 74].

Название бренда может формировать каламбур, как в случае популярной венесуэльской рекламы гигиенических средств для детей Melody:

(16) Melody: "Melody, melody, me lo dijo mi mamá (букв.: Melody, Melody, мне сказала это моя мама).

Телевизионная реклама этих средств всегда сопровождается запоминающимся джинглом, что также ассоциативно связано с названием бренда (Melody - англ.: мелодия).

Ассоциативная связь проявляется и в следующих слоганах.

(17) Bach: Una obertura memorable (Запоминающаяся увертюра).

Остроумие слогана в (17) обнаруживается в обыгрывании связей между фамилией великого композитора, названием бренда и лексемой obertura, которая фонетически напоминает другую лексему - apertura.

(18) Bach: sinfonía en rojo (Симфония в красном).

Sinfonía en rojo - это обыгрывание выражений типа «симфония ре-минор», уточняющих тональность музыкальных произведений. В данном случае игра слов не возникла бы, если бы название вина не имело никакого отношения к музыке. Высказывание могло бы восприниматься как интересная метафора, но все же никаких игровых ассоциаций оно бы не породило. Пример (18) демонстрирует отличие товарно-ориентированной игры слов от брендово-ориентированной.

(19) Magno: Un poco de Magno es mucho (Heмного Magno - это много).

Использованная в качестве названия коньяка лексема magno (великий) семантически связана с такими лексемами, как grande (большой, великий), реquесо (маленький) и 
mucho (много). Поэтому в слогане возникает парадокс, основанный на противопоставлении антонимов росо и тисho. Тем самым создатели рекламы дают понять адресату, что даже небольшого количества данного коньяка достаточно для того, чтобы получить удовольствие.

(20) B. The Travel Brand: Caribe empieza con $\boldsymbol{B}$ (Карибы начинаются с B).

В этом случае парадокс возникает в силу нарушения логики и очевидности высказывания: любой человек понимает, что в метаязыковом смысле слово Caribe не начинается на букву В. Однако от нас требуется осознание того, что именно путешествие на Карибы начинается с посещения офиса данной компании. Слоган эффективен потому, что он привлекает внимание своей парадоксальностью, реципиент задается справедливым вопросом «Почему Карибы начинаются с В?» и, обнаружив правильную интерпретацию, запоминает бренд B. Travel.

Стоит отметить, что само название бренда зачастую создается таким образом, чтобы его можно было удачно обыграть в рекламе на разных языках: жизнь);

(21) Renault Captur: Captura la vida (Поймай

(22) Yatekomo: Kómete el mundo en un ya (Съешь весь мир за одно мгновение).

Название автомобиля Renault Captur (21) созвучно императиву испанского глагола capturar (захватывать, ловить), а название лапши быстрого приготовления Yatekomo (22) фразе ya te como (я сейчас тебя съем).

III. Под несвязанной игрой слов понимается обыгрывание общих понятий, напрямую никак не связанных ни с брендом, ни с наименованием товара, рекламируемого в слогане. Наиболее часто данный тип представляет собой намеренное использование полисемии и омонимии, парадоксальных выражений, а также парономазии, причем иногда достаточно примитивной. Особенность таких слоганов заключается в том, что в большинстве случаев их можно без изменений применять в рекламе любой продукции, так как никаких ассоциативных связей между то- варом и игрой слов не существует. Проанализируем примеры игры слов, относящейся к данному типу:

(23) McDonalds: Feliz Novedad (Счастливого Рождества + Новшества);

(24) Hero Baby: Hecho con ciencia. Hecho a conciencia (Сделано с умом. Сделано на совесть);

(25) Lienzo de los Gazules: Con mucho gusto, con poco gasto (С большим удовольствием, с малыми затратами);

(26) Hoy por Hoy - Francino: Pase lo que pase un paso por delante (Будь что будет, мы сделаем шаг вперед);

(27) Pengeot: Si le importa la tecnología, no la importe (Если для вас важна технология, не импортируйте еe);

(28) Coca Cola: La gente normal que rara es (Нормальные люди - какие же они странные / как же они редко встречаются).

Как видим, игра слов в указанных слоганах лишь частично затрагивает специфику рекламируемой продукции, при этом некоторые слоганы могут быть взаимозаменяемыми. Так, слоган (23) может быть использован любой компанией, если она рекламирует какие-либо особые новые предложения, приуроченные к Рождеству (Navidad). В слогане (24) два омонимичных словосочетания Hecho con ciencia и Hecho a conciencia можно применить к любому товару, производитель которого захочет подчеркнуть связь между используемыми в производстве новыми технологиями и бережным отношением производителя к продукции, поскольку ничто в слогане не указывает нам на то, что его объект - детское питание. Из рекламного сообщения Lienzo de los Gazules (25) также невозможно догадаться, чем занимается данная компания - реципиенту только дают понять, что товар ему должен понравиться, а денег на него он потратит немного.

Если реципиенту предоставить слоганы с игрой слов третьего типа, он может только предположить, что в них рекламируется: например, слоган (26) можно поместить в категорию СМИ, которые освещают ежедневную ситуацию в стране или в мире, а продукция, рекламируемая в слогане (27), может быть помещена в категорию высокотехнологичных товаров. Однако слоганы типа La gente normal que rara es (28) вряд ли можно сопоставить с 
каким-либо видом товара ввиду того, что в них ни имплицитно, ни эксплицитно не выражен объект рекламы. Единственное, что возможно - считать этот текст попыткой заинтересовать молодых, креативных людей, которые рассматривают «нормальность» и конформизм как нечто отрицательное. При этом противопоставление двух значений слова raro (редкий как не частотный и редкий как необычный) часто используется создателями рекламы, в том числе социальной:

(29) Federación Española de Enfermedades Raras: Enfermedades raras, más frecuentes de lo que imaginas (Редкие заболевания встречаются чаще, чем ты думаешь).

\section{Заключение}

Таким образом, в испаноязычной рекламе можно четко выделить три типа игры слов в соответствии с характером обыгрываемого объекта. В результате анализа 607 слоганов, содержащих игру слов, было выяснено, что товарно-ориентированная игра слов содержится в 399 слоганах ( $\approx 66 \%$ ), брендовоориентированная используется в 161 слогане ( $\approx 26 \%$ ), а несвязанная - в 47 рекламных слоганах $(\approx 8 \%)$.

Наибольшим когнитивно-прагматическим потенциалом обладает брендово-ориентированная игра слов, так как она способствует запоминанию самого бренда и позволяет выделить его на общем фоне продукции такого же назначения. Товарно-ориентированная игра слов имеет меньший когнитивно-прагматический потенциал ввиду использования в ней уже устоявшихся ассоциаций, существующих у коммуникантов. Меньшая частотность брендово-ориентированной игры слов, возможно, обусловлена, во-первых, тем, что слоганы, содержащие название бренда, могут восприниматься реципиентами как явная манипуляция (например, в [Dass, Kohli, Kumar, Thomas, 2014, p. 2510] приводятся результаты эксперимента, подтверждающего, что прямое включение бренда в слоган негативно влияет на восприятие слогана реципиентами). Однако необходимость связывания бренда и рекламного текста является одним из важных условий создания эффективного слогана
[Kohli, Leuthesser, Suri, 2007, p. 420]. Во-вторых, создание брендово-ориентированной игры слов требует больших усилий по сравнению с товарно-ориентированной, так как само слово-бренд не всегда имеет смысл в испанском языке или вызывает определенные положительные ассоциации у его носителей.

Наименее частотный тип игры слов (несвязанный) обладает наименьшим когнитивно-прагматическим потенциалом и может быть использован прежде всего с целью развлечения реципиента.

В качестве перспектив исследования можно указать применение данной классификации к материалу рекламы на других языках, а также экспериментальное подтверждение гипотезы о том, что товарно-ориентированная и брендово-ориентированная игра слов оказывают большее влияние на реципиентов, чем несвязанная игра слов.

\section{СПИСОК ЛИТЕРАТУРЫ}

Арутюнова Н. Д., 1999. Язык и мир человека. М. : Языки русской культуры. 896 с.

Ильясова С. В., Амири Л. П., 2016. Язык СМИ и рекламы: игра как норма и как аномалия. М. : Флинта : Наука. 328 с.

Карповская Н. В., 2015. Когнитивно-прагматический потенциал средств категории интенсивности сквозь призму процесса метафоризации (на материале интенсификатов испанского и русского языков) // Известия Южного федерального университета. Филологические науки. № 3. С. 107-117.

Dass M., Kohli C., Kumar P., Thomas S., 2014. A study of the antecedents of slogan liking // Journal of Business Research. № 67. P. 2504-2511. DOI: 10.1016/j.jbusres.2014.05.004.

Glowicka M., 2002. Figuras de repetición por juego de palabras en los eslóganes publicitarios de la prensa española actual // Etudes romanes de Brno. № 1. P. 61-69.

Kohli C., Leuthesser L., Suri R., 2007. Got slogan? Guidelines for creating effective slogans // Business Horizons. Vol. 55, № 5. P. 415-422. DOI: 10.1016/j.jbushor.2007.05.002.

Tanaka K., 1992. The pun in advertising: A pragmatic approach // Lingua. № 87. P. 91-102.

Van Mulken M., Van Enschot-van Dijk R., Hoeken H., 2005. Puns, relevance and appreciation in advertisements // Journal of Pragmatics. № 37. P. 707-721. DOI: 10.1016/j.pragma.2004.09.008. 
Xiang L., 2006. On the pun in English advertisement // Canadian Social Science. 2006. Vol. 2, № 2. P. 68-70.

Yan Y., 2015. Analysis of puns in English advertising language from the relevance theory // Sino-US English Teaching. Vol. 12, № 8. P. 602-607. DOI: 10.17265/1539-8072/2015.08.008.

Yus F., 2003. Humor and the search for relevance // Journal of Pragmatics. № 35. P. 1295-1331. DOI: 10.1016/S0378-2166(02)00179-0.

\section{REFERENCES}

Arutyunova N.D., 1999. Language and the human world. Moscow, Yazyki russkoy kultury Publ. $896 \mathrm{p}$.

Ilyasova S.V., Amiri L.P., 2016. The language of media and advertising: wordplay as a norm and as an anomaly. Moscow, Flinta; Nauka Publ. 328 p.

Karpovskaya N.V., 2015. Cognitive and pragmatic potential of intensity category means in the process of metaphorization (on the material of Spanish and Russian intensifiers). Izvestiya Yuzhnogo federalnogo universiteta. Filologicheskie nauki [Proceedings of Southern Federal University. Philology], no. 3, pp. 107-117.
Dass M., Kohli C., Kumar P., Thomas S., 2014. A study of the antecedents of slogan liking. Journal of Business Research, no. 67, pp. 2504-2511. DOI: 10.1016/j.jbusres.2014.05.004.

Glowicka M., 2002. Figuras de repeticiyn por juego de palabras en los eslyganes publicitarios de la prensa espacola actual. Etudes romanes de Brno, no. 1, pp. 61-69.

Kohli C., Leuthesser L., Suri R., 2007. Got slogan? Guidelines for creating effective slogans. Business Horizons, vol. 55, no. 5, pp. 415-422. DOI: 10.1016/j.jbushor.2007.05.002.

Tanaka K., 1992. The pun in advertising: A pragmatic approach. Lingua, no. 87, pp. 91-102.

Van Mulken M., Van Enschot-van Dijk R., Hoeken H., 2005. Puns, relevance and appreciation in advertisements. Journal of Pragmatics, no. 37, pp. 707-721. DOI: 10.1016/j.pragma.2004.09.008.

Xiang L., 2006. On the Pun in English Advertisement. Canadian Social Science, vol. 2, no. 2, pp. 68-70.

Yan Y., 2015. Analysis of puns in English advertising language from the relevance theory. Sino-US English Teaching, vol. 12, no. 8, pp. 602-607. DOI:10.17265/1539-8072/2015.08.008.

Yus F., 2003. Humor and the search for relevance. Journal of Pragmatics, no. 35, pp. 1295-1331. DOI: 10.1016/S0378-2166(02)00179-0.

\section{Information about the Author}

Aleksandr V. Dzyuba, Lecturer, Department of Ibero-American Philology and Communication Studies, Southern Federal University, Bolshaya Sadovaya St., 105, 344006 Rostov-on-Don, Russia, aleksandr.dziuba@mail.ru, https://orcid.org/0000-0001-8655-997X

\section{Информация об авторе}

Александр Владимирович Дзюба, преподаватель кафедры иберо-американской филологии и коммуникативистики, Южный федеральный университет, ул. Большая Садовая, 105, 344006 г. Ростов-на-Дону, Россия, aleksandr.dziuba@mail.ru, https://orcid.org/0000-0001-8655-997X 